http://www.jfas.info

\title{
THE STRATEGY DIFFERENCES AND MOVEMENT PATTERN BETWEEN MEDALIST AND NON-MEDALIST TAEKWONDO YOUTH ATHLETE
}

P. K. Suppiah ${ }^{1, *}$, A. J. Joummy ${ }^{1}$, M. R. Abdullah, ${ }^{2,3}$, A. B. H. M. Maliki ${ }^{3}$, R. M. Musa ${ }^{3}$, S. M. Mat-Rasid $^{2}$, A. Adnan ${ }^{3}$, N. A. Kosni ${ }^{3}$ and H. Juahir ${ }^{2}$

${ }^{1}$ Faculty of Psychology and Educational Studies, Universiti Malaysia Sabah, 88400 Sabah, Malaysia

${ }^{2}$ East Coast Environmental Research Institute (ESERI), Universiti Sultan Zainal Abidin, 21300 Terengganu, Malaysia

${ }^{3}$ Faculty of Applied Social Sciences, Universiti Sultan Zainal Abidin, 21300 Terengganu, Malaysia

Published online: 08 August 2017

\begin{abstract}
The objective of current study is to compare the strategy differences and movement pattern between medalist and non-medalist Malaysia Taekwondo youth athlete. A total of 17 matches of Tenom, Sabah Taekwondo Championship were recorded for notation analysis and movement strategy by using Kinovea which involving 20 male Sabah athletes of the category 15-17 years. The medalists is defined as they advanced for the knockout phase temporarily non-medalist are not. There is a significant different between medalist and non-medalist $(\mathrm{U}=$ 19.500, $\mathrm{z}=-2.340, \mathrm{p}=0.019, \mathrm{r}=0.504)$ on the variability of attacking technique. Moreover, reverse spin movement shown a significant $(\mathrm{U}=24.000, \mathrm{z}=-2.123, \mathrm{p}=0.034, \mathrm{r}=0.41)$ different between medalist and non-medalist in attacking strategy.
\end{abstract}

Author Correspondence, e-mail: pathmaha2@gmail.com

doi: http://dx.doi.org/10.4314/jfas.v9i2s.61 
Notational and motion analysis reveal a secret behind successful of medalist in attacking strategy and movement in a combat sport.

Keywords: combat sports; strategy and movement; medalist and non-medalist; notation and motion analysis.

\section{INTRODUCTION}

Taekwondo is one of the combat sports and can be described as a modern Olympic sport that required high intensity, to defeat the exponent using precise and quick kicks [1]. Among classical taekwondo competitions types (i.e. sparring, patterns, and breaking) sparring are the only categories in the Olympic being held. In the sparring event, athletes are required to use appropriate techniques as stated by the rules before starting the fighting. However, in the taekwondo sparring competition, athletes will compete in weight divisions. Taekwondo matches take place in three rounds of three minutes with one-minute rest interval between each round [2].

There are three types of taekwondo kicking technique which is, circular kick, linear and spin. Circular kick involves the movement of legs swung back toward the exponent for example roundhouse [2]. Similarly, involving linear foot kick straight forward movement towards the exponent for example pushing. Spin kick involving the movement that requires the body to make a round back for instance. Marks will be given when the athletes managed to kick and kick touched by the authorized body. Location kick determines the total score they get. One point is given for a legitimate attack, which hit the trunk protective equipment. Two points will be awarded if a spin kick is legitimate and is touched with protective equipment trunk. Three points have been granted for legal strikes and hit the head. Four points are given for the attack turning right kick and hit on the head.

Ability to score with particular movement and strategies in competitive situations demands the need for continued efforts to study in this area. Tactical strategy also known as fighting knowledge is one of the key elements of professional fighters [3]. Contrasting from other non-motor components, fighting knowledge in sports is unique as it involves combinations of ability to select an appropriate strategy for the situation and also the successful execution of 
the skill within a short period [4]. Study in sparring Taekwondo competition had led to some interesting findings. For example, it has been reported that the most frequent used kicking technique is roundhouse kick and the finding is consistently reported by former researcher [5]. The numerous use of the roundhouse kick was due its mechanical benefit [6]. Specifically, it can produce a comparatively complex momentum on impact than other techniques of kick and thus provided an excellent chance of stunning an exponent. Though the roundhouse kick was the frequently recorded technique in the competitions, the capability to score with this technique was not always evident $[5,7]$.

The notational analysis system is the classical analysis method that could be applied to describe the technical profile of athletes as well as the technical skills kick utilized in taekwondo [8-10]. The method of analysis of an athlete's skills is necessary to help athletes enhance their abilities and increase the chances for success [2]. Prior study has been conducted using notational analysis in taekwondo to describe fighting strategies and movement. For instance, in the 2008 Taekwondo Championship held in Taiwan has been reported that the capability for the fighters to score with the roundhouse kick was top among all other techniques that have been used [7]. Nevertheless, some discrepancies were reported on Taekwondo medalist at the same study which found that exponent's ability to score with the cut down kick was the highest trailed by the roundhouse kick [5]. Hereafter, the usefulness of notational analysis in sparring Taekwondo competition reveals the discrepancy between the frequently used kick and the capability to score with the particular kick in competitive situations which demands the need for continued efforts to study fighting strategies. To this extent, this study designed to analyze the differences in strategy and movement pattern between medalist and non-medalist in Malaysia Taekwondo youth exponents.

\section{MATERIALS AND METHODS}

\subsection{Participants}

Participant for this study is the athletes who made it into quarter-final rounds. Successful athletes who qualified for the next round will be referred as a medalist athletes, while the non-qualified athletes will be referred as non-medalist. This study comprises of 20 male 
athletes in the age category of 15 to 17 years $($ Fin $=8$, Bantam $=8$, Feather $=4)$. The study was carried out during Taekwondo Championships in Tenom, Sabah.

\subsection{Procedure}

The instrument used in this study is a video camera (Samsung EK-GC100 Galaxy Camera and Digital Video Camcorder). The recording device will be placed $5 \mathrm{~m}$ away from the tennis matches with camera tripod height is $1.5 \mathrm{~m}$ (see Fig. 1). This video will be analyzed using Statwatch software for the notation analysis and it has been carried out by one person only. Fragment of the film (recorded) is used to analyze the fighting strategic been applied on the both medalist and non-medalist respectively for 17 matches throughout the competition.

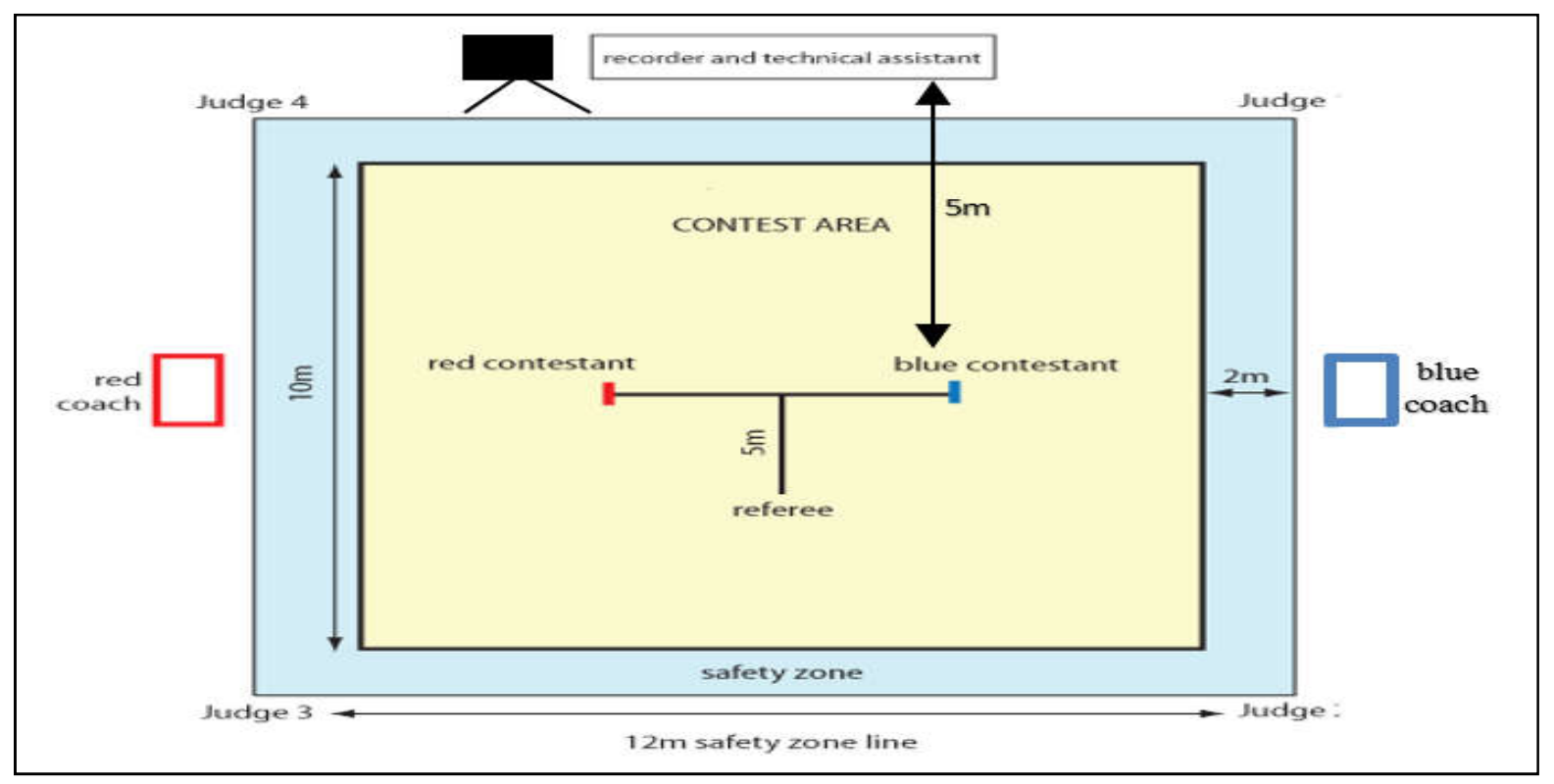

Fig.1. A design of a camera placement in taekwondo court

\subsection{Data Analysis}

In prior main data analysis, the total of missing data, data error, and outlier were checked to facilitate an analysis [11]. Distribution of normality data as well as outlier were tested using Kolmogorov-Smirnov and box-plot method [12]. The difference effect size (r) is measured by the number of mean and standard deviation as recommended by the former researcher [13]. Effect size below $<0.20$ consider very small effect size, 0.20 to 0.49 consider as a small effect size, 0.50 to 0.79 consider as an average effect size and $\geq 0.80$ consider as a large effect size. The consideration of this value is an according to the conventional interpretation of Cohen's. All of the statistical analysis will be obtained through SPSS version 21. 


\section{RESULT}

Based on the descriptive statistic in Table 1, group medalist is more likely to use circular kick (roundhouse kick and double roundhouse kick) obtaining by $47 \%$. Next, both linear (push, side and cut down kick) and spin kick (back, spin and reverse spin kick) for medalist group acquired $39 \%$ and $14 \%$ respectively. On the other hand, the non-medalist group also tend to apply circular kick in the sparring game which is acquired $56 \%$ for the most frequent technique in the match. Subsequently, both linear (push, side and cut down kick) and spin kick (back, spin, and reverse spin kick) for non-medalist group acquired $36 \%$ and $8 \%$ respectively.

Attacking parameter that has been analyzed in this study is roundhouse, side, push, cut down, reverse, double roundhouse, back side, reverse spin and punching. Based on Table 1, the most frequent attacking technique for medalist is roundhouse kick namely by $42 \%$ while cut down kick by $30 \%$, push and reverse spin kick obtain the same amount which is as much as $7 \%$. For the meantime, group non-medalist are also more likely to use techniques roundhouse kick in this match namely by $49 \%$ while cut down a kick by $24 \%$, and kick push as much as $5.5 \%$ (see Fig. 2).

Table 1. Descriptive analysis of attacks by the medalist $(n=10)$ and non-medalist $(n=10)$ for the age category 15 to 17 years

\begin{tabular}{ccc}
\hline Attack Techniques & Medalist (\%) & Non-Medalist (\%) \\
\hline Roundhouse kick & 42 & 49 \\
Sidekick & 2 & 1 \\
Push kick & 7 & 11 \\
Cut down kick & 30 & 24 \\
Reverse kick & 1 & 0 \\
Double roundhouse kick & 5 & 7 \\
Backside kick & 7 & 6 \\
Reverse spin kick & 6 & 2 \\
Collision & 0 & 0 \\
\hline
\end{tabular}




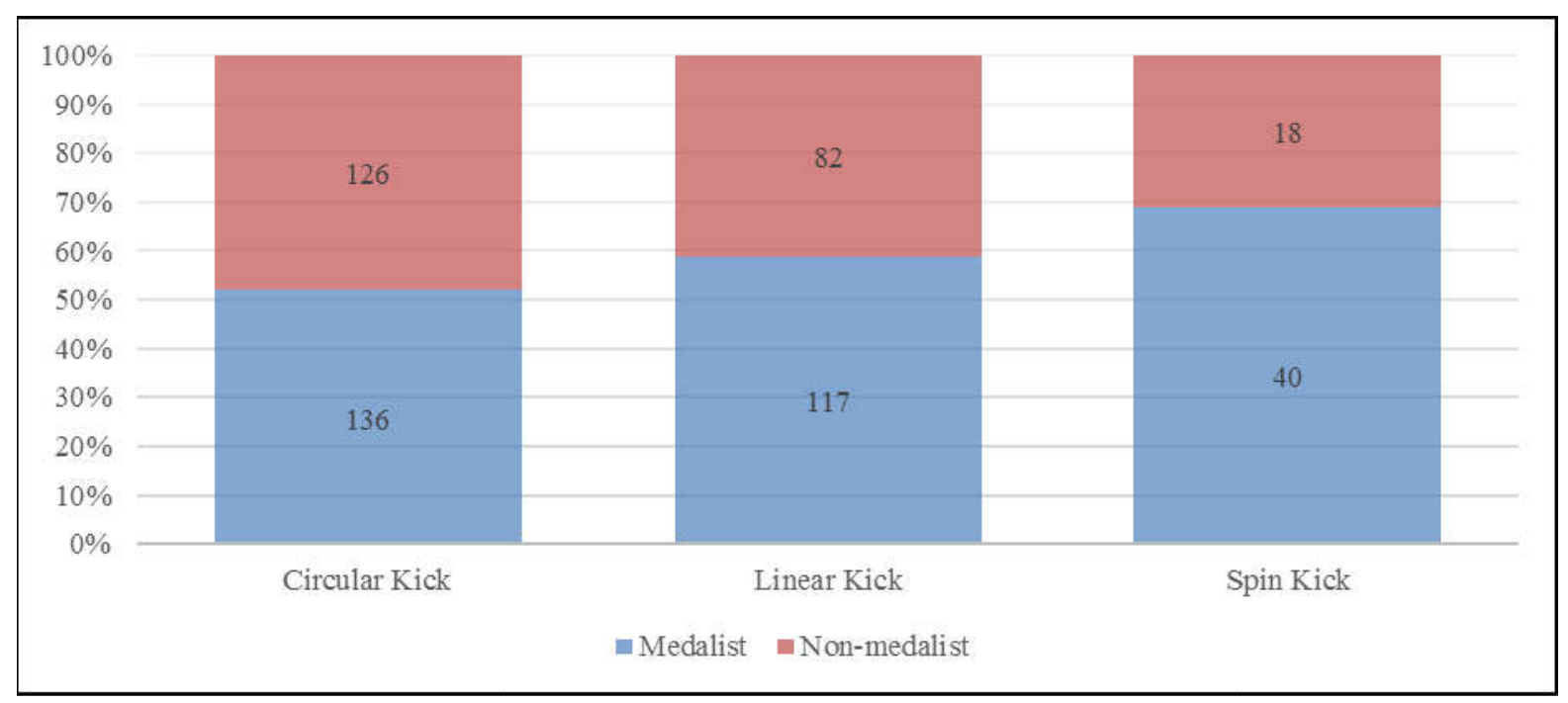

Fig.2. Percentage and frequency data of attacks by the medalist and non-medalist

There are nine types of attacks that an annotation in this study. In Taekwondo competition (e.g. sparring), not all the types of attack techniques used by athletes. It depends on the choice of the athletes themselves. Medalist is more likely to use this type of attacking technique that varies in competition than non-medalist. From nine types of attacks that were analyzed, $61 \%$ of various attacking has been used by medalist while non-medalist emphasize only $39 \%$ of attacks. Table 2 shows that there are significant differences in the use of attacking among medalist compare to non-medalist $(\mathrm{U}=19,500, \mathrm{z}=-2340, \mathrm{p}=0.019, \mathrm{r}=0.504)$. It projected that group of medalist is more likely to use different techniques in the rather than group non-medalist. According to Cohen's score, the effect size of 0.50 is considered as an average effect size of differences. Further analysis for the various attacking differences between medalist and non-medalist were examined to understand the pattern of attacking style.

Table 2. The difference between the use of attack between medalist and non-medalist for the age category 15 to 17 years

\begin{tabular}{ccccc}
\hline Age Category & $\mathbf{U}$ & $\mathbf{Z}$ & P Value & Effect Size (r) \\
\hline 15 to 17 year & 19.500 & -2.340 & 0.019 & 0.504 \\
\hline
\end{tabular}

The variation of attacking in Taekwondo sparring strategy has been shown to be a predictor in term of discriminating between medalist and non-medalist. Table 3 demonstrated that out of nine various fighting strategy has been used by fighters, only reverse spin kick technique shows significant differences between medalist and non-medalist $(\mathrm{N}=24,000, \mathrm{z}=-2123, \mathrm{p}=$ 
$0.034, \mathrm{r}=0.41)$. It is clearly noted that medalist is more likely to use a reverse spin kick in the match rather than non-medalist. Table 3 also provide information regarding the effect size (r) of the reverse spin kick technique which is $r=0.406$ and according to Cohen's score, the effect size considered as a small effect size of differences between medalist and non-medalist. On the other side, push kick technique obtains effect size very low which is -0.055 .

Table 3. The difference of attack between medalist $(n=10)$ and non-medalist $(n=10)$ for the age category (15 To 17 Years).

\begin{tabular}{ccccc}
\hline Attack Techniques & $\mathbf{U}$ & $\mathbf{Z}$ & $\mathbf{P}$ & ES (r) \\
\hline Roundhouse kick & 43.000 & -0.531 & 0.596 & 0.063 \\
Side kick & 31.000 & -1.640 & 0.101 & 0.322 \\
Push kick & 44.500 & -0.427 & 0.669 & -0.055 \\
Cut down kick & 33.000 & -1.293 & 0.196 & 0.266 \\
Reverse kick & 49.500 & -0.73 & 0.942 & 0.140 \\
Double roundhouse kick & 48.000 & -0.161 & 0.872 & -0.024 \\
Backside kick & 39.000 & -0.873 & 0.383 & 0.162 \\
Reverse spin kick & 24.500 & -2.123 & 0.034 & 0.406 \\
\hline
\end{tabular}

\section{DISCUSSION}

This study aimed to analyze the differences of strategy and movement between medalist and non-medalist in Malaysia Taekwondo youth athlete. Fighting strategy is a set of intelligent pattern of tactical knowledge response by powerful, quick movement and these attributes can differentiate between medalist and non-medalist in the competitive match. This strategy also refers to the type of technique that very essential typically to earn points in Taekwondo sparring match.

Finding from this study give an objective information regarding the frequently kicking technique (fighting strategy) have been used in game, which is parallel with prior researchers [14-15]. Group medalist and non-medalist in the competition frequently utilize their expertise in circular kick to earn points compare to linear and spin kick techniques such as roundhouse kick, which is has been reported as the fastest kick technique compared to other techniques 
(see Fig. 3) [16-17]. Furthermore, because of biomechanical effectiveness in producing roundhouse kick technique make this technique as the main fighting strategy and movement that frequently used in sparring match [17]. Additionally, in the sport of taekwondo, the speed and strength is the key to earning points/scores in the competition.

From this study, it revealed that cut down kick is also a technique that frequently been used for medalist group. This technique aims to target bigger point which is kicking an exponent in the head only (see Fig. 3). Although, the production of this technique harder than roundhouse kick, but athletes prefer to use it because of they can likely score. Typically, athletes can effectively kick using cut down technique when their exponent is either taller or shorter. This technique created with the set of physical fitness characteristic ability which is hip flexibility, muscle power and whip-like movement [18]. Furthermore, the prior researcher has shown meaningful evidence in taekwondo area that medalist (e.g. athletes with higher ranked) constitute greater power and agility which is will lead them to produce cut down kick technique in Taekwondo sparring competition rather than non-medalist [19].

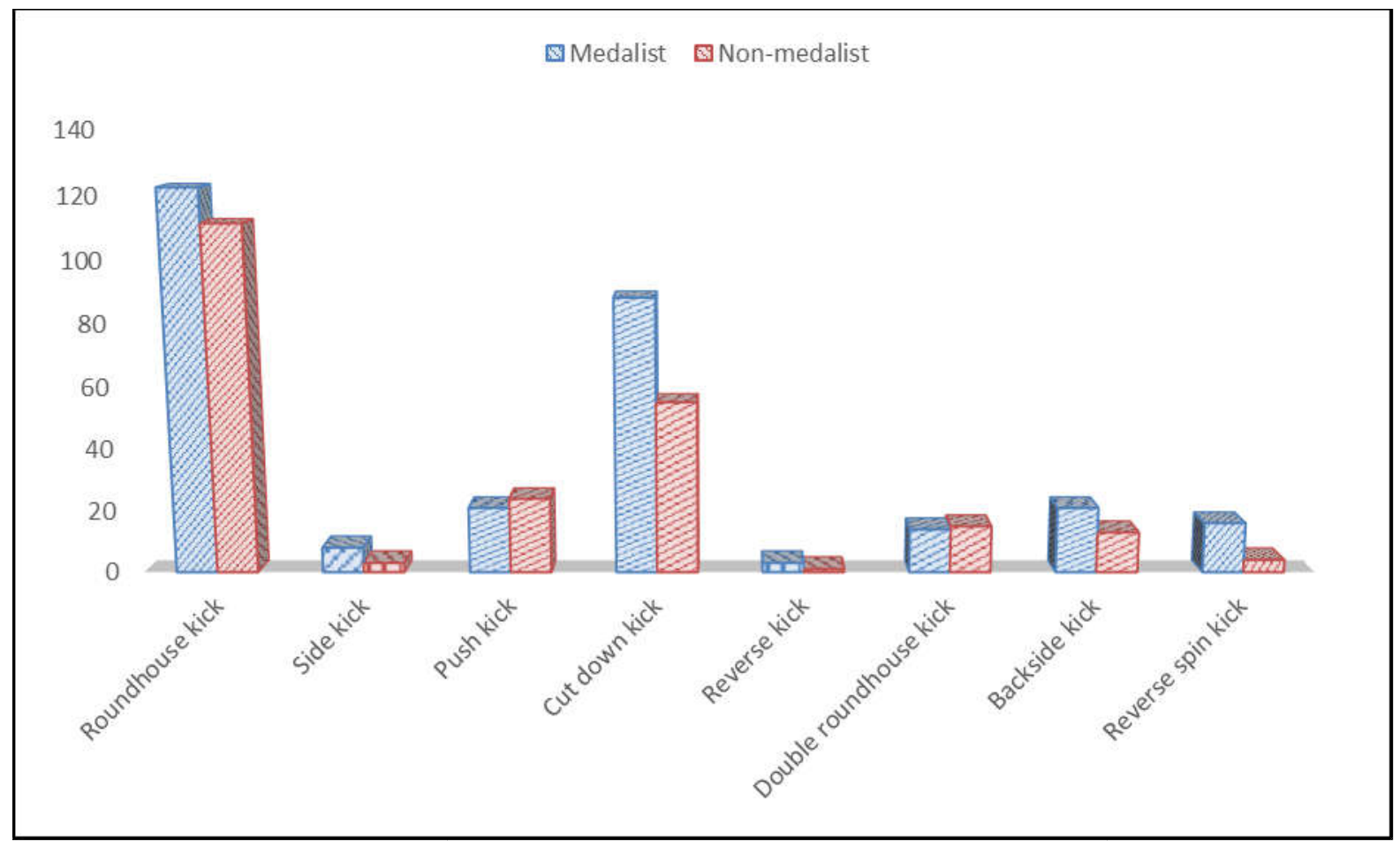

Fig.3. Differences of attack between medalist and non-medalist

Even though the effect size of the difference between medalist and non-medalist is average, the finding projected that medalist is more likely to use the technique of reverse spin kick in 
the match against the non-medalist. Body balance is important in producing a reverse spinning kick. After implementing this type of round kick technique, athletes need a good body balance to prevent falls. If athletes fall, they will be warned (Kyong-go) from the referee. Failure for athletes to maintain body balance after performing round kick techniques also cause athletes to be in a dangerous situation because it will open their weakness point if the exponent applies counter-attack. Athletes prone to lose their ability to protect themselves from exponent counter-attack when they are difficult to control their body balance. Therefore, athletes who have the technique or poor health rarely use spin kick in the match. Implementation of this reverse spin kick of attacking in fighting strategy gives an advantage for medalist to earn high points.

Group medalist is more likely to use different techniques in the game compared to the non-medalist group. This finding is in concordance with prior research that group medalist are more likely to use different types of attacks in the game compared to non-medalist. Diversify attack strategy can give an advantage to athletes such as response time can make it difficult for exponents to fight back a response to the attack [17]. According to the previous study, the results of the reaction time will be longer if the number of stimulus-response (variation) that much [20]. Therefore, athletes should take a longer time to anticipate the action or reaction of a respondent if the exponent uses a variety of kicks. Elite athletes will also diversify their attacks to increase the chances of winning.

\section{CONCLUSION}

Notational and motion analysis revealed that significant differences in fighting strategies existed between medalist and non-medalist. Medalist group tended to use more advanced fighting strategies in the game and these fighting strategies allowed medalists to earn more marks/points in the game than the non-medalists. Nevertheless, to implement these skills during competitions, an extensive level of mastery ability as well as physical fitness is vital. Therefore, for fighters to gain a better chance of winning medals, coaches must certify that their fighters work on these characteristics so as to be competent in using these fighting strategies in competitions. 


\section{ACKNOWLEDGEMENTS}

The researchers of this paper wish to acknowledge the coaches, managers, Malaysia Taekwondo Association (MTAWTF) as well as United Taekwondo Sabah Association (TM/WTF) for their support and contribution to the accomplishment of this research.

\section{REFERENCES}

[1] Pettersson S, Ekström M P, Berg C M. Practices of weight regulation among elite athletes in combat sports: A matter of mental advantage? Journal of Athletic Training, 2013, 48(1):99-108

[2] Falco C, Landeo R, Menescardi C, Bermejo J L, Estevan I. Match analysis in a university taekwondo championship. Advances in Physical Education, 2012, 2(1):28-31

[3] Starkes J. L., Ericsson K. A. Expert performance in sports: Advances in research on sport expertise. Illinois: Human Kinetics Publishers, 2003

[4] Starkes J L. Motor experts: Opening thoughts. Advances in Psychology, 1993, 102:3-16

[5] Matsushigue K A, Hartmann K, Franchini E. Taekwondo: Physiological responses and match analysis. Journal of Strength and Conditioning Research, 2009, 23(4):1112-1117

[6] Tornello F, Capranica L, Minganti C, Chiodo S, Condello G, Tessitore A. Technical-tactical analysis of youth Olympic Taekwondo combat. Journal of Strength and Conditioning Research, 2014, 28(4):1151-1157

[7] Chou K M, Chiu M J. Research of Taekwondo attack score actions and areas: 2008 National Presidential Taekwondo Championship Final Games of female division. Sports Coaching Science, 2009, 15:11-22

[8] Kazemi M, Waalen J, Morgan C, White A R. A profile of Olympic taekwondo competitors. Journal of Sports Science and Medicine, 2006, 1(5):114-121

[9] Kazemi M, Casella C, Perri G. 2004 Olympic taekwondo athlete profile. Journal of the Canadian Chiropractic Association, 2004, 53(2):144-152

[10] Kazemi M, Perri G, Soave D. A profile of 2008 Olympic taekwondo competitors. Journal of the Canadian Chiropractic Association, 2010, 54(4):243-249

[11] Abdullah M R, Musa R M, Maliki A B, Kosni N A, Suppiah P K. Role of psychological 
factors on the performance of elite soccer players. Journal of Physical Education and Sport, 2016, 16(1):170-176

[12] Abdullah M R, Maliki M, Husin A B, Musa R M, Kosni N A, Juahir H, Haque M. Multi-hierarchical pattern recognition of athlete's relative performance as a criterion for predicting potential athletes. Journal of Young Pharmacists, 2016, 8(4):463-470

[13] Elias N F. Measuring the impact of information systems in Malaysia. International Journal on Advanced Science, Engineering and Information Technology, 2011, 1(2):206-211

[14] Pieter F, Pieter W. Speed and force in selected taekwondo techniques. Biology of Sport, $1995,12: 257-266$

[15] Falco C, Alvarez O, Castillo I, Estevan I, Martos J, Mugarra F, Iradi A. Influence of the distance in a roundhouse kick's execution time and impact force in taekwondo. Journal of Biomechanics, 2009, 42(3):242-248

[16] Abdullah M R, Eswaramoorthi V, Musa R M, Maliki A B H M, Kosni N A, Haque M. The effectiveness of aerobic exercises at difference intensities of managing blood pressure in essential hypertensive information technology officers. Journal of Young Pharmacists, 2016, $8(4): 483-486$

[17] Menescardi C, Lopez-Lopez J A, Falco C, Hernandez-Mendo A, Estevan I. Tactical aspects of a National university taekwondo championship in relation to round and match outcome. Journal of Strength and Conditioning Research, 2015, 29(2):466-471

[18] McPherson S. L. Tactics: Using knowledge to enhance sport performance. London: Routledge, 2008

[19] Ghorbanzadeh B, Münđroğlu S, Akalan C, Khodadadi M R, Kđrazci S, Şahđn M. Determination of taekwondo national team selection criterions by measuring physical and physiological parameters. Annals of Biological Research, 2011, 2(2):184-197

[20] Hick W E. On the rate of gain of information. Quarterly Journal of Experimental Psychology, 1952, 4(1):11-26

\section{How to cite this article:}

Suppiah PK, Joummy AJ, Abdullah MR, Maliki ABHM, Musa RM, Mat-Rasid SM, Adnan A, Kosni NA, JuahirH. The strategy differences and movement pattern between medalist and non-medalist taekwondo youth athlete. J. Fundam. Appl. Sci., 2017, 9(2S), 858-868. 